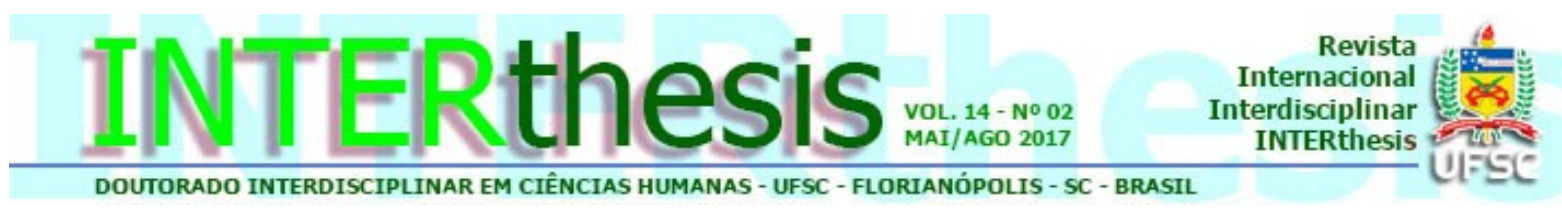

\title{
PARADOXOS DO DISCURSO CAPITALISTA: UM NOVO SUJEITO?
}

\section{Resumo:}

Lilian Clementoni Batista $^{1}$

Este artigo propõe, a partir da teoria dos discursos de Jacques Lacan, um questionamento sobre o discurso capitalista na forma do matema que foi apresentado em 1972, ocasião da Conferência de Milão. O discurso capitalista já havia sido mencionado anteriormente, porém sob outra forma por Lacan, sobretudo no seminário 17, "O avesso da psicanálise" (1969/1970), quando o apontou como uma variante do discurso do mestre. Nesse contexto, o autor sempre se referiu a esse discurso ressaltando a diferença entre o mestre moderno (capitalista) e o mestre tradicional (senhor), mas ambos ocupando posições semelhantes, ou seja, revelando uma mesma configuração de relação no laço social. Já em 1972, na conferência supracitada, Lacan propôs o matema do discurso capitalista, no entanto, salientou que essa forma estaria condenada a consumir a si própria, portanto, a não sustentar sua própria existência. Questionamos então a possibilidade de existência do discurso capitalista como expressão de uma forma inédita de relação do sujeito jamais ocorrida em outro momento histórico.

Palavras-chave: Mais-valia. Mais-de-gozar. Discurso capitalista, Marx. Lacan.

\section{INTRODUÇÃO}

Na Conferência de Milão, em 1972, Lacan propõe uma nova forma discursiva para além das quatro antes teorizadas. Esse discurso seria o Discurso Capitalista, que já havia sido citado anteriormente como uma variante do discurso do mestre, de modo que o antigo mestre tradicional (senhor) seria substituído pelo mestre moderno (capitalista), porém ambos expressando uma mesma forma de laço. Contudo, nessa ocasião em 1972, Lacan formaliza um novo matema para expressar o Discurso Capitalista, fazendo uma pequena inversão de elementos que seria o indicativo de grande diferença no modo do sujeito se relacionar. Mas, nessa mesma apresentação, Lacan discorre sobre a astúcia dessa forma discursiva e argumenta que ela está destinada a se consumir, ela não sustentaria sua própria existência. 0 psicanalista afirma que na pequena inversão no matema, dada entre sujeito e

\footnotetext{
${ }^{1}$ Mestre em Psicologia Social pela Pontifícia Universidade Católica de São Paulo, São Paulo, SP. Pesquisa financiada pelo CNPq. Psicóloga atuando na Associação Paulista para o Desenvolvimento da Medicina, Hospital São Paulo em São Paulo, SP, Brasil. E-mail: lilianclem@hotmail.com
} 
significante mestre, reside a insustentabilidade dessa forma, pois ela marcha rapidamente e acaba por consumir a si própria. O sujeito, no lugar de agente, estaria diretamente ligado na produção, onde o mais-de-gozar (a) se posiciona, e não haveria uma barra que faria esse impedimento de acesso ao gozo através do objeto causa de desejo, o que se assemelha ao matema da fantasia: $\$ \triangleright \mathbf{a}$. O considerado "acesso" ao objeto causa de desejo, inexistente em outros discursos nos quais há sempre uma impossibilidade que permite os giros discursivos, provém da falta da barra que liga o sujeito ao mais-de-gozar. Isso faz com que essa forma seja compreendida como a expressão da relação de consumo que os indivíduos têm na atualidade: um sujeito ligado diretamente ao produto, um sujeito sem limites, determinado por uma incessante falta a gozar. Essa leitura é quase sempre associada à compreensão da forma capitalista atual como capitalismo de consumo, o que questionaremos adiante.

Segundo Braunstein (2010), a passagem do mestre tradicional para o mestre moderno, capitalista, expressa a mudança de um mestre que era da repressão para um outro, que comanda o gozo, sob a forma do discurso capitalista. O autor aponta que essa nova modalidade de discurso foi, inicialmente, proposta por Lacan "como se estivesse brincando, como se fosse um capricho pessoal ao qual poderia renunciar se quisesse" (BRAUNSTEIN, 2010, p. 148). A ideia de que nesse discurso não existe impossibilidade entre o sujeito e o objeto causa de desejo, associada ao anúncio de Lacan de que essa forma está fadada a consumir a si própria, pode ser expressa nos objetos produzidos pelo capital, que, para manter o ritmo da produção, faz objetos que tendem a uma obsolescência estritamente material e também na desejabilidade provocada por meio dos recursos propagandísticos e ideológicos que permeiam a tendência à homogeneização dos supostos objetos de desejo no capitalismo. Braunstein refere como "servomecanismos para designar esses artefatos que a ciência permite fabricar e enviar ao mercado para o seu consumo massivo e que estão destinados a rápida obsolecência [...] que sob essa forma discursiva funcionariam análogos ao objeto a" (BRAUNSTEIN, 2010,p. 149). De acordo com a elucidação do autor, no discurso capitalista o \$ aparece ocupando o lugar do agente, assim como no discurso histérico. Contudo, argumenta que se nesse último a histérica se dirige ao mestre (vetor $\$ \rightarrow \$ 1$ ), ou seja, ao outro, no discurso capitalista, ao contrário, o sujeito não se dirige a nenhum outro (no caso, o 
proletário), estando também dissociado do saber. Braunstein chega a questionar se seria cabível nomear "discurso" a uma fórmula na qual um agente não se dirige a um outro. No discurso capitalista, quem opera no lugar do agente, assim como no discurso histérico, é o sujeito, com toda "sua incurável divisão", conforme o autor indica. Porém, no discurso capitalista não é o sujeito que se dirige ao saber (S2) para que produza objetos (a). O significante mestre, no lugar da verdade, é quem continua ordenando: ele se dirige ao saber, que operando sob uma forma científica, produz os objetos desejáveis, os servomecanismos. Então o autor elucida que "o discurso capitalista inscreve essa "verdade" ocupando o seu lugar, abaixo e à esquerda do significante mestre $\mathrm{S} 1$. "O sujeito, na cegueira de suas demandas, sem sabê-lo inconsciente, acreditando na força de seu 'eu', faz atuar na ordem do mestre. O agente do discurso capitalista (\$) "faz semblante" de ser o mestre, acredita não estar sujeitado a nada" (BRAUNSTEIN, 2010 p. 152). Ao fazer a análise desse discurso, Braunstein retoma o argumento de Guy Lérès, para quem Lacan faz do Saber a verdadeira dominante do discurso do mestre moderno, apoiado pela burocracia, o que consequentemente ao compreender o Saber como dominante, não seria coisa diferente do discurso universitário.

\begin{abstract}
Por isso podemos sustentar, ratificando Lérès, que o discurso capitalista tem a sua fórmula no seio dos quatro discursos e ela não é outra coisa senão a do discurso universitário, no qual o saber toma o lugar do agente que repete e comunica os ditames do mestre, dirigindo-se a um outro que já não é o escravo senão o proletário anônimo, sem rosto, sempre substituível, imagem mesma do objeto a. (vetor $\mathrm{S} 2 \rightarrow \mathrm{a}$ no discurso universitário). É possível dar-se conta da novidade que implica o discurso capitalista, o discurso do mestre moderno, mostrando sua equivalência com o discurso universitário... e os discursos continuam sendo quatro. E assim não é mais necessário mais que o "rigor da leitura [do matema] em pedaços". Essa revisão crítica do "quinto discurso" era necessária para fazer entrar em cena um novo aspirante a um lugar próprio na dança dos discursos e logo mostrar que, também ele, estava já previsto no esquema original dos quatros discursos de 1970. (BRAUNSTEIN, 2010, p. 154)
\end{abstract}

\title{
2 “NÃO SÃO TRINTA E SEIS POSSIBILIDADES, SÃO APENAS QUATRO".
}

Na mesma conferência em que Lacan propõe o novo matema, o psicanalista reafirma que o discurso é o que faz laço, que é o que trata o gozo, e reafirma sua teoria de que são apenas quatro. Braunstein argumenta que "ao escrever uma versão ligeiramente distinta do discurso do mestre, Lacan estava aludindo - e ao mesmo tempo vetando - a um quinto discurso, que tinha subvertido suas próprias formulações" (BRAUNSTEIN, 2010, p. 150). Nesse momento, tendemos a uma consideração mais cautelosa sobre esse novo matema proposto, cujas R. Inter. Interdisc. INTERthesis, Florianópolis, v.14, n.2, p.39-56 Mai.-Ago. 2017 
interpretações posteriores continuam a semear controvérsias sob sua forma. Parece que essas controvérsias e indagações são o propósito de Lacan ao afirmar que os discursos são apenas quatro ao mesmo tempo que propõe essa variação no discurso do mestre, que apesar de ser "uma pequena inversão" gerou grandes desencontros. Lacan nunca deixou de reafirmar a força que o discurso do mestre e o discurso universitário têm na atualidade, o que em algumas passagens o psicanalista parece nos dar pistas sobre a necessidade de uma análise mais profunda sobre o que ele mesmo provocaria posteriormente com a sua novidade. $O$ vigor com que o discurso do mestre ainda se apresenta nas relações contemporâneas é assinalado por Lacan (1969-1970) no seminário 17:

Estas observações têm o objetivo de provocar-lhes espanto e levá-los pelo menos a esta pergunta relativa ao discurso do mestre - como é que esse discurso, que se escuta tão maravilhosamente bem, pode ter mantido sua denominação? Isto é provado pelo fato de que, explorados ou não, os trabalhadores trabalhem... Jamais se honrou tanto o trabalho, desde que a humanidade existe. E mesmo, está fora de cogitação que não se trabalhe. Isto é um sucesso, então, do que chamo do discurso do mestre. (p. 178)

E logo depois, faz a seguinte observação sobre o discurso universitário:

Indaguemos agora como pode esta sociedade, dita capitalista, proporcionarse o luxo de se permitir um enfraquecimento do discurso universitário. Tal discurso não passa, contudo, de uma dessas transformações que the exponho em detalhe. É o giro de um quarto em relação ao discurso do mestre. Daí uma pergunta que vale a pena considerar - concordando com esse enfraquecimento, será que não se cai numa armadilha? Não é uma idéia nova. (p. 178)

Estaria aí nos alertando Lacan sobre a armadilha que seria entender o enfraquecimento do discurso universitário em favor da prevalência do discurso capitalista? Nos dois trechos acima podemos deduzir a concordância de Lacan sobre a incidência predominante dessas duas formas de discurso (discurso do mestre e discurso universitário) na atualidade. Sobretudo no segundo, a respeito do discurso universitário, Lacan parece prever o engodo e a polêmica que ele próprio que iria provocar poucos anos depois- e que se estendem até hoje - com a fórmula do discurso capitalista. E, para acalentar nossas dúvidas, está o dito de Lacan dois anos após a proposição dessa inversão: "Tanto menos que, ao relacionar essa miséria ao discurso capitalista, eu o denuncio. Indico apenas que não posso fazê-lo seriamente pois ao denunciá-lo estou reforçando-o - por normá-lo, ou seja, aperfeiçoá-lo". (LACAN. 1974, p. 30). 
Evidentemente, Lacan marca durante todo o seminário 17 a mudança entre as relações que se davam num nível senhor-escravo para capitalista-proletário, o que é expresso por meio de um quarto de giro do discurso do mestre para o discurso universitário. Não há uma forma única de discurso prevalecente, mas sim a coexistência dessas formas, que podem se manifestar com maior ou menor vigor em uma época. Ainda insistimos sobre a expressividade dessas duas formas: discurso do mestre e discurso universitário. Sobre o discurso universitário, Lacan diz que o significante mestre está mais inatacável - o que não significa inexistente - devido à dificuldade de sua localização, por estar dissolvido nas relações: "[...] o significantemestre, por terem sido dissipadas as nuvens de impotência, aparece como mais „inatacável", justamente na sua impossibilidade. Onde está ele? Como nomeá-lo?” (LACAN, 1969-1970, p. 189). Embora quase que invisível, o significante mestre no discurso universitário continua exercendo o autoritarismo em nome de um pseudosaber materializado, por exemplo, nas pesquisas científicas, que a cada dia prescrevem sobre a vida e se propagam na produção e mercado, citando de passagem a indústria farmacêutica como uma de suas expressões, entre tantas outras.

Em uma outra passagem, no mesmo seminário, Lacan insiste na obturação existente entre o lugar da verdade e da produção, em quaisquer formulações e modos discursivos existentes:

\begin{abstract}
Quaisquer que sejam os sinais, os significantes-mestres que vêm se inscrever no lugar do agente, a produção não tem, em qualquer caso, relação alguma com a verdade. Pode-se fazer tudo o que quiser, pode-se dizer tudo o que quiser, pode-se tentar conjugar essa produção com as necessidades, que são necessidades que se forjam, mas não adianta. Entre a existência de um mestre e a relação de uma produção com a verdade, não há como sair disso. (p. 185)
\end{abstract}

Teria Lacan, poucos anos depois de proferir essas palavras, as anulado diante da postulação do novo matema, caracterizado pela ausência de impossibilidade? Não é o que nos parece tendo em vista o que ele afirmou momentos depois de exibir a controversa fórmula na Conferência de Milão. Pouco após apresentar o discurso capitalista na lousa, aborda sobre o que seria um discurso: o discurso é o que se pode produzir pela existência da linguagem, e tem como função fazer o laço social. E na sequência adverte que "não há trinta e seis possibilidades, existem somente quatro". Daí percebemos a dimensão do paradoxo apresentado quanto aos matemas.

R. Inter. Interdisc. INTERthesis, Florianópolis, v.14, n.2, p.39-56 Mai.-Ago. 2017 


\section{DISCURSO CAPITALISTA, PRODUÇÃO E CONSUMO}

Comumente se entende o discurso capitalista como o discurso do consumo, em que o objeto causa de desejo no lugar da produção interpela o sujeito sem obstáculos. Contudo, seria válido um apontamento sobre a lógica do funcionamento capitalista. Como vimos anteriormente, o que deseja o capitalista é que a produção não pare, pois assim aumenta a extração de mais-valia, já que sabemos que o capitalista, tendo o objetivo de acumulação de capital, aliena o valor de uso da mercadoria para ter o seu valor de troca. $O$ capitalista faz a renúncia ao gozo visando um acúmulo, o que na homologia com o discurso do mestre podemos entender como a renúncia ao gozo para que se renove a produção de mais-degozar.

Dentro da relações capitalistas, de acordo com Marx (1980), valor do produto, contém apenas o valor do tempo de trabalho socialmente necessário, conceito que utiliza para expressar o valor necessário para que a força de trabalho, ou seja, a sobrevivência do trabalhador, se mantenha e se reproduza, de acordo com as condições histórico-culturais vigentes. Estariam incluídas nesse cálculo necessidades fisiológicas, como alimentação, sono, habitação, etc, e necessidades culturais e históricas, que modificam de acordo com o contexto social. Ou seja, o trabalho excedente, o "a mais" que certamente foi trabalhado mas não pago ao trabalhador é apropriado pelo capitalista, já que ele comprou a força de trabalho por completo mas pagou por ela apenas o salário, que é muito inferior ao valor que o trabalho agregou ao produto. Assim, como diz Marx, "o capitalista prevê a situação que o faz sorrir" (MARX, 1980, p.227). Ao incorporar força de trabalho "viva" à materialidade morta de outros elementos no produto, ele produz valor, cujo excedente é todo seu, portanto, a mais-valia.

\footnotetext{
Ao se converter dinheiro em mercadorias que servem de elementos materiais de novo produto ou de fatores do processo de trabalho vivo à materialidade morta desses elementos, transforma-se valor, trabalho pretérito, materializado, morto, em capital, em valor que se amplia, um monstro animado que começa a 'trabalhar', como se tivesse o diabo no corpo. (MARX, 1890, p.228)
}

Como assinala Marx, nesse processo, não importa se o trabalho é simples ou mais elaborado, se demanda esforço físico ou psíquico, se é considerado superior ou inferior. Comparado com o trabalho social médio, o trabalho considerado superior é formado com custos mais altos, requer mais tempo para ser produzido. No R. Inter. Interdisc. INTERthesis, Florianópolis, v.14, n.2, p.39-56 Mai.-Ago. 2017 
processo desse trabalho materializam-se, no mesmo espaço de tempo, valores proporcionalmente elevados. Então não se distingue a mais-valia pela natureza do trabalho, a mais-valia se origina de um excedente quantitativo do trabalho, seja ele qual for.

Retomando sobre a ideia comum de que o discurso capitalista revela mudança no modo que o capitalismo se apresenta na contemporaneidade: teria havido uma mutação na forma de extração de mais-valia e acúmulo de capital nos dias atuais? Nesse ponto em questão, concordamos que tanto o discurso capitalista quanto o sistema capitalista tendem a se consumir, conforme teorizam Lacan e Marx, respectivamente. Contudo, a produção dos objetos pelo capital continua a ser condição sine qua non do consumo, pois, o consumo frenético dos tempos atuais é sustentado por um modelo específico de produção. E como nos diz a teoria de Marx (1890), é nisso que se encontra a mola mestra do acúmulo de capital: quando a forma de trabalho agrega valor durante a transformação do produto e possibilita a extração de mais-valia.

O consumo, evidentemente, é trabalhado por estratégias publicitárias cada vez mais refinadas. Contudo, o consumo em relação à produção pode ainda ser a ponta do iceberg. Um ponto que merece atenção redobrada seria que, ao entender o discurso capitalista como o discurso do consumo, o cerne das análises se desloca da produção para o consumo, tirando o foco da mais-valia, posição amplamente propagada e defendida na atualidade em diversos campos do saber. Sobre isso, Netto e Braz (2006) convocam-nos a pensar:

\begin{abstract}
Nos últimos trinta anos, a própria centralidade do trabalho vem sendo posta em questão por algumas correntes de peso das Ciências Sociais: a partir da constatação estatística de dois fenômenos de visibilidade desde os anos oitenta do século passado - a redução do contingente dos trabalhadores alocados à produção de bens materiais e o crescente desemprego que afeta praticamente todas as sociedades capitalistas contemporâneas teóricos de posições diversas sustentam, propondo soluções analíticas muito diferentes, que o trabalho já não se constitui mais como eixo a partir do qual se organiza a vida social. Tornou-se frequente, nos meios acadêmicos, o discurso acerca do "fim do trabalho", do "fim da sociedade do trabalho" assim como a referência à "sociedade (ou economia) do conhecimento" - discurso associado às várias ideologias ditas pósmodernas. Aqueles dois fenômenos (a redução da demanda de trabalhadores para a produção de bens materiais e o desemprego crescente) são perfeitamente compreensíveis quando se considera a dinâmica essencial da sociedade capitalista e, devidamente analisados, não autorizam a desconsideração da centralidade do trabalho. (p. 60)
\end{abstract}

E logo depois:

R. Inter. Interdisc. INTERthesis, Florianópolis, v.14, n.2, p.39-56 Mai.-Ago. 2017 
O fato de parte das Ciências Sociais, em face dos limites da sociedade burguesa, não contribuírem para a sua crítica, mas, ao contrário, colaborarem para desqualificar o trabalho como um valor superado", esse fato é eloquente acerca da função legitimadora e apologética dessa parcela de disciplinas acadêmicas. (p. 61)

Netto e Braz reafirmam a centralidade da produção dentre todas as esferas que permeiam a vida social, assim como a teoria marxiana, contudo assinalam que para que os bens produzidos pela produção capitalista cumpram sua função, devem ser distribuídos (repartidos) e consumidos. Em relação à repartição, esclarecem que isso depende do regime de propriedade e das relações fundamentais: se a propriedade é coletiva, a repartição tende a ser igualitária; se é privada, "tende a ser profundamente desigual (como nos modos de produção que sucederam a partir da dissolução da sociedade primitiva). O exame referido, assim, comprova que as relações de distribuição são determinadas pelas relações de produção" (p. 74). No mesmo sentido, o consumo também depende da forma de produção: "a forma do consumo não é aleatória, mas conectada ao próprio objeto; enfim, é a produção de novos valores de uso que cria novas necessidades de consumo" (p. 74).

Os trechos citados acima nos trazem a dimensão de quanto o consumo está condicionado a um sistema produtivo. Portanto, longe de excluir a centralidade da produção e do trabalho em favor dos moldes de consumo, eles nos fornecem a chave para sua compreensão. No discurso do mestre e também no novo matema do discurso capitalista, o objeto (a) no lugar da produção expressa o mais-de-gozar, em homologia com a mais-valia. Se no capitalismo a mais-valia é o objetivo do capitalista, assim como o mais-de-gozar representa a produção do escravo interpelado pelo mestre, parece haver uma contradição no entendimento que a causa de desejo seja apenas o consumo, e não o mais-de-gozar. Pois se assim fosse, o que representaria o a, objeto causa de desejo, no lugar da produção, já não seria o mesmo, o mais-de-gozar. Essa inversão no lugar da produção Lacan não fez.

Para a teoria marxiana, a mais-valia não está no produto final, nem é produzida no ato do consumo, quando a mercadoria se realiza. A mais-valia é gerada e extraída da força de trabalho durante o processo produtivo e está relacionada ao acúmulo de capital, e não ao consumo, embora obviamente esse seja um componente do funcionamento do capitalismo. 
Não desconsideramos que o consumismo típico da contemporaneidade seja uma das formas de repetição do inconsciente na tentativa de recuperar algo que se supõe perdido. No entanto, está ao lado de inúmeros outros sintomas que nos convocam a perceber a mesma estrutura que demanda a repetição. Como exemplo, temos os sujeitos que consomem excessivamente, mas também os que retêm, cuja repetição, ao contrário de "consumir", esteja localizada em "acumular"; já outros em "trabalhar", "amar", "controlar", "submeter"; e na sequência teríamos uma lista cuja capacidade significante dos sujeitos de desejo a faria infinita. Como vimos anteriormente, Lacan extrai da teoria marxiana o conceito de mais-valia como base de seu conceito de mais-de-gozar, o qual a partir daí compõe a estrutura dos discursos, sobretudo o discurso do mestre. No entanto, o discurso do mestre é o discurso do inconsciente, aquele com o qual o sujeito emerge, portanto, é universal, transistórico. Então entendemos que embora homólogos, uma diferenciação se faz inevitável: mais-valia é uma formação histórica, que emerge com a produção capitalista; já o mais-de-gozar é transistórico, existente desde que há sujeito. Se entendemos que no discurso capitalista o sujeito está livremente ligado ao mais-degozar, uma contradição emerge pois, se esse conceito se refere ao inassimilável no lugar da produção, entender o acesso do sujeito a esse resto inassimilável, sob a forma do consumo, parece complicado. Indagamos então o porquê a mesma impossibilidade que se apresenta em todas as outras relações seria aí suprimida. A atribuição de uma totalização ao objeto do consumo não parece ser diferente de interpelar o Outro como ocorre em outras relações, tais como na relação com o saber, na relação com o outro como objeto de amor, entre várias, estando todas elas condicionadas a uma impossibilidade e atravessado pelo Outro, conforme os discursos nos sugerem: "A relação sexual não existe".

\section{O DISCURSO CAPITALISTA DEFRONTE AO LAÇO SOCIAL, AO OUTRO, ÀS COISAS DO AMOR...}

O discurso capitalista descrito sobre o novo matema seria aquele que não promoveria o laço social, conforme apontado por Lacan. Nesse discurso o agente (sujeito) não se endereça ao Outro, este apenas ocupa o lugar de semblante enquanto o significante-mestre no lugar da verdade convoca que o saber, no lugar do Outro, produza o mais-de gozar. Então se entende, por essa ausência de endereçamento ao Outro, que sob esse suposto discurso não haveria laços entre R. Inter. Interdisc. INTERthesis, Florianópolis, v.14, n.2, p.39-56 Mai.-Ago. 2017 
humanos, ou seja, ele não promoveria o laço social. O discurso capitalista apenas ligaria o sujeito com o objeto, com o mais-de-gozar. Nessa compreensão, o laço social não seria promovido porque há apenas a incidência do objeto causa de desejo sobre todos os sujeitos, em detrimento da relação com o Outro.

Daí emerge a ideia comum de que sob essa forma o sujeito no capitalismo estaria desligado do Outro, que esse discurso não promoveria laço social, estando o indivíduo movido pelo insaciável da falta a gozar produzida pelo capitalismo. Entendemos que a proposta de Lacan sobre esse discurso, defrontada com o cuidado que ele próprio toma em não condecorar essa forma, exige nosso cuidado para não endossá-la, muito menos para considerá-la como forma discursiva única. Essa tese do sujeito desligado do Outro se desencontra de toda a teoria sobre a constituição do sujeito a partir da alienação ao Outro e, inevitavelmente inserido no laço social. Se entendemos o laço social inerente e necessário à constituição do sujeito, a compreensão sugerida pelo discurso capitalista leva a uma complexa colocação: haveria um sujeito próprio do capitalismo, um novo sujeito, que possui um funcionamento peculiar quando defrontado com o sujeito que perpassa toda a história da cultura? Haveria uma nova constituição de sujeito, ao qual é foracluída a castração e o consequente endereçamento ao Outro em detrimento de uma compreensão de estrutura transistórica? Haveria uma nova forma, possível de ser sustentada fora da relação com o Outro e do laço social, conforme nos sugere esse novo matema? Alguns estudos nesse sentido advogam que os sujeitos anteriores ao capitalismo da forma contemporânea estariam imersos no laço social, enquanto os "sujeitos do capitalismo de consumo", conforme essas leituras, não conseguiriam estabelecer laços. Essas leituras compreendem que o sujeito atual é incapaz de se relacionar, sendo que seu objetivo seria fazer laço, como um casamento duradouro, uma família, a despeito de outras épocas, em que o indivíduo supostamente queria se livrar dos vínculos consistentes. Além da ausência de laço, algumas interpretações tendem a um entendimento de que dentre os sujeitos, não mais os neuróticos expressos na alienação ao outro de um tempo anterior, haveria uma "tendência à perversão", quando não considerada de todo: uma "perversão generalizada". A desalienação ao Outro em favor da relação imediata com o objeto sugerida pelo discurso capitalista também sustenta a ideia tão comum de queda da autoridade, ou queda da função paterna, diferentemente do que é lido no discurso 
do mestre e no discurso universitário. Sobre essa colocação, temos alguns questionamentos. Estariam os laços sociais em outras épocas tão consolidados que isso se refletiria na estrutura familiar ou essa insolubilidade dos casamentos, como exemplo, respondia também às exigências culturais e institucionais? $E$ na atualidade, evidentemente em formas diversas, não haveria laço entre as relações, variando das formas mais concretamente autoritárias até as mais dissimuladas, inclusive nos casamentos? $\mathrm{Na}$ contemporaneidade, embora talvez vigore $\mathrm{O}$ autoritarismo dissimulado (o que entendemos como discurso universitário), as formas autoritárias concretas ainda saltam aos nossos olhos, tal como vemos nas religiões, desde a católica que permeia séculos até as mais modernas, como as igrejas evangélicas ou neopentecostais que vêm ganhando espaço, inclusive na política. Nos laços conjugais, entendemos que a neurose que envolve a alienação ao Outro continua presente assim como em outros momentos históricos, dos quais a clínica e a vida cotidiana nos dão exemplos da atualidade e a literatura da história. Além disso, podemos constatar o quanto a instituição casamento ainda tem um peso social. E, após recorrermos tanto à questão da mais-valia, não podemos deixar de mencionar os laços trabalhistas, de como se configuram em suas leis, desde quem as redige, que na maior parte está do lado do patronato; além da alienação ao Outro encarnado no chefe, na empresa, na própria marca; e, sobretudo, o laço entre os trabalhadores que, a despeito de serem ocultados e marginalizados pela grande mídia, estão atuantes em movimentos sociais, grevistas, entre outros. Nesse caso Askofaré (1991) nos dá um exemplo:

A verdade, certamente se impõe no descrédito da razão e certas
racionalidades se denunciam como puras racionalizações, basta ver a
repressão com sangue da greve dos ferroviários, que vem desmentir o
universalismo do direito de greve, mas jamais o laço social do próprio
trabalho que faz manter os corpos juntos é posto em causa pela greve; a
selvageria da exploração, os abusos ou os excessos na expoliação do gozo,
sim. (p. 175-176)

Entendemos que não existe um cinismo ou uma tendência à perversão que vigoram. Embora algumas instituições e sujeitos possam tomar essa forma, não podemos compreendê-las de modo generalizado. Isso seria contrário tanto a uma concepção de classe social quanto da singularidade de cada sujeito e de toda construção teórica sobre sua constituição. Se o discurso capitalista exclui as coisas do amor, o que logicamente envolve a exclusão da castração, lembramos que Lacan na construção de sua teoria nos elucida que toda demanda é, no seu íntimo, 
demanda de amor. Esse entendimento, que constitui um dos pilares da clínica, também está em xeque na concepção de um novo discurso que desfaz o laço. Um desdobramento que pode decorrer dessa forma discursiva que não promove o laço seria entendê-la incidente sobre a violência e as atrocidades na atualidade. A esse propósito, argumentamos que a segregação é inerente também ao próprio laço social, que a forma econômica capitalista e a ideologia científica tendem a acentuála de uma maneira particular, porém o fazem dentro do próprio laço. O Outro está encarnado na materialidade que nos circunda, na relação com o trabalho, nos encontros amorosos - inclusive na falta deles -, nas instituições, religião, família, exemplos que a clínica nos oferece. Porém, talvez por estar mais oculto em algumas formas sociais, incluindo nelas o fator classe social, o grande Outro encarnado nas relações nem sempre fica evidente. Braunstein (2010), ao discorrer sobre o discurso capitalista, faz a seguinte ressalva:

Partimos de um ponto convencionalmente aceito e por isso mesmo suspeito: a fenomenologia de uma vida cambiante nas sociedades chamadas pós-industriais que tanto e quão banalmente faz cócegas na maioria dos estudiosos, arrebatados pelos inesperados feitiços e ameaças apocalípticas da contemporaneidade técnica, social e política. Esse acúmulo de abruptas novidades parece indicar novas orientações e horizontes. O cacofônico discurso que escutamos e que com frequência nos ensurdece, proveniente de mil alto-falantes, seria o fenômeno revelador de novas posições subjetivas, às quais teríamos que aplicar as potências do pensar no sentido heideggeriano. $A$ isso a psicanálise não pode renunciar: $a$ considerar as condições de sua clínica (da transferência) em cada momento da história. Sem esquecer que (bem poderia ser esse o caso) talvez nada haja de inusitado e nossas impressões acerca das transformações radicais na vida humana sejam meras extensões de nossa fantasia. Não seria essa a primeira vez que a montanha de dados ilumina algo ínfimo, esconde a essência do que parece revelar. Ou que nos fascinamos como uma "novidade": o sol ilumina desde o começo dos tempos. (p. 146)

Essa passagem nos alerta sobre um possível equívoco ocorrido diante do acirramento do capitalismo em suas formas mais atuais: o choque que as formas contemporâneas nos provoca tende a interpretações de que o capitalismo de agora seria outro, não mais aquele teorizado por Marx. Evidentemente sua forma atual é mais refinada, mesmo porque busca predominantemente a extração de mais-valia relativa de um modo extremamente aprimorado comparado com os primeiros rastros industriais. Isso não significa que seja coisa diversa da primeira. O entendimento em questão, além de mudar o foco da práxis proposta para objeção ao capitalismo, tende a uma concepção catastrófica, pois ao deslocar o cerne da questão para a relação do sujeito com o consumo - um sujeito sem Outro e fora do laço - aponta 
em direção a uma perversão generalizada em um suposta "pós-modernidade", uma visão apocalíptica que ao cair em um niilismo que ata as mãos, nada mais faz que colaborar e se aliar ao funcionamento capitalista. Pacheco Filho (2012) argumenta que a ideia de substituição de um supereu repressivo por um supereu que convoca ao gozo que supostamente permearia a contemporaneidade, assim como algumas outras ideias semelhantes, se desencontra com toda a construção teórica da psicanálise, o que se torna um problema epistemológico. $E$, para além da falha epistemológica mencionada, envolve consequências desastrosas tanto para a psicanálise clínica quanto em uma esfera de atuação política. O autor destaca que Lacan, na construção de sua teoria, traz em sua obra questões que articulam o sujeito ao social, sendo que "desde a primeira fase de sua obra concebe a subversão psicanalítica do sujeito a partir das ideias de "inconsciente como discurso do Outro" e "desejo como desejo do Outro", representando-o topologicamente por meio de modelos em que não é possível distinguir-se interior de exterior (como é o caso da banda de Moebius)" (p. 205). Pacheco Filho ainda assinala que muitos psicanalistas fizeram algumas formulações que trazem um equívoco de pretender um ponto de ruptura de toda a teoria: o advento de um novo sujeito. A esse respeito, o autor elucida o desencontro epistemológico que permearia esse tipo de formulação com toda a construção teórica da psicanálise, não somente em relação à teoria de Lacan, mas também à de Freud. Entre essas novas ideias, o autor ressalta: "queda do simbólico", "declínio da função paterna", "sujeito pós-moderno", "perversão generalizada", "condição pós-humana" e "substituição de um supereu repressivo por um supereu que convoca ao gozo". Essas novas ideias recorreriam à concepção de um novo sujeito inexistente ao longo da história da humanidade. Daí novamente perguntamos: diante de todas as nuances culturais que perpassam a história da humanidade, teria o capitalismo produzido um outro sujeito, diferente do sujeito que a própria psicanálise se empenhou em teorizar? Haveria um novo sujeito que foge do funcionamento do inconsciente, cuja formalização foi traçada cuidadosamente desde Freud e sucessivamente por Lacan e outros psicanalistas? Pacheco Filho compreende que essa hipótese seria a "preferência por se conjecturar uma modificação na estrutura do sujeito, em lugar de se enfatizarem as transformações discursivas (no laço social) que surgiram nas novas circunstâncias históricas" (p. 203). O autor ainda elabora que o que há de subversivo na psicanálise está 
justamente relacionado aos conceitos de sujeito e objeto, neles incluídos o inconsciente, o desejo, a falta e o gozo, sem os quais a psicanálise e toda subversão que a compreende não existiriam. Assim, faz a seguinte advertência sobre a proposição de novos conceitos, tais como um outro sujeito próprio do capitalismo em detrimento do enfrentamento do problema de pesquisa:

[...] em substituição à busca de resolução dos enigmas de pesquisa ou quebra cabeças que eles constituem para a já consolidada concepção de sujeito da psicanálise, esconde um perigo importante para o campo [...] refiro-me à fragmentação do campo: um problema recorrente que há muito merece ser objeto de maior atenção dos psicanalistas interessados em que seu campo não se dissolva por pulverização. (p. 192)

O autor, sobre o suposto novo discurso, elucida:

Aquilo que Lacan se refere quando menciona o discurso do capitalismo independente das controvérsias sobre se constitui ou não um quinto discurso ou uma versão modificada de um dos outros quatro - mostra a forma particular em que, em nossa época, se exerce a mestria do discurso: capitalista e operário são as versões contemporâneas do Senhor e do Escravo. E a fetichização das relações entre os objetos (fetichismo da mercadoria) constitui a forma contemporânea pela qual se exercem as relações de dominação entre os sujeitos. (p. 194)

Pacheco Filho adverte que, além dos problemas diante dos conceitos fundamentais da psicanálise, as novas formas de interpretação em questão, ao não se atentarem para as determinações históricas e formas discursivas como reguladoras de gozo, desconsideram o capitalismo como forma histórica de sociedade. Ao conceber o discurso capitalista, o significante-mestre é considerado inatacável, no sentido em que não haveria impedimento que possibilitaria um giro discursivo. Essas formas deslizam para uma concepção catastrófica da situação contemporânea, de modo que não haveria saídas para o modus operandi do capitalismo e da configuração da subjetividade que permeia os laços sob esse sistema. A perspectiva que desconsidera a existência de laço social, consequentemente desconsidera a existência de luta de classes. Isso se torna algo perigoso, pois ao negar a presença de conflito entre as classes sociais, não aposta que aí estaria a possibilidade de saída, conforme sustenta toda a teoria de Marx. Por meio desses apontamentos, a evidência de que essas configurações que aqui mencionamos destrata a teoria marxiana nos dá fôlego para insistir no cuidado que elas demandam, já que podem cair na concepção catastrófica de que o discurso capitalista é um discurso sem saída, o que se contrapõe à teorização de Marx de que o capitalismo está condenado a destruir a si próprio e também a de Lacan R. Inter. Interdisc. INTERthesis, Florianópolis, v.14, n.2, p.39-56 Mai.-Ago. 2017 
(1972), que afirma que o discurso capitalista não se sustenta, indicando o discurso analítico como a possibilidade de saída. Diante das considerações tecidas até aqui, nos deparamos com a necessidade de cautela ao entender o discurso capitalista como uma nova forma discursiva, relembrando um apontamento de Braunstein: de que uma forma que não se dirige ao outro talvez não devesse ser nomeada discurso. Também ressaltamos a estratégia que o próprio Lacan realiza em não consagrá-lo imediatamente como novo discurso, o que a ambivalência de sua proposição nos alerta. Mesmo no caso de ser considerado um discurso em vigor na nossa sociedade atual, conforme Cevasco (2007) o faz, o discurso capitalista não deve ser lido como forma única em detrimento dos demais, pois os discursos coexistem, conforme vimos ao longo da pesquisa. Nesse sentido a autora elucida:

Pueden tener una formación social donde diversos discursos, no
forzosamente son todos hegemónicos. En la URSS el discurso hegemónico
era el discurso universitario, en la sociedad antigua era el discurso del amo,
en nuestra sociedad es el discurso capitalista, pero eso no quiere decir que
únicamente sea el discurso capitalista, porque entra en combinación com el
discurso universitario y con el discurso del amo. Esto es una cuestión de
política y de sociologia, las formaciones sociales no están bajo el dominio
de un solo discurso. Este es muchas veces el equivoco que hacen analistas
actualmente, a mi entender. Al lado del discurso capitalista hay otros
discursos y el discurso capitalista coexiste con otras formas discursivas que
muchas veces son un tratamiento de los impasses del discurso capitalista
mismo como dominante. Esto para decirles, que cualquier análisis
coyuntural de una formación social necesita hacer una revisión de los
discursos que circulan en la sociedad, y cuáles son los discursos
dominantes en un momento, y cuando permutan. (p. 59)

\section{CONSIDERAÇÕES FINAIS}

Frente às questões elaboradas, consideramos que o discurso capitalista deve ser discutido, contudo, com as mesmas ressalvas que faz Lacan ao enunciá-lo e questioná-lo: "Indico apenas que não posso fazê-lo seriamente pois ao denunciá-lo estou reforçando-o - por normá-lo, ou seja, aperfeiçoá-lo" (LACAN, 1974, p. 30).

Não podemos ignorar a força dos quatro discursos apresentados no seminário 17, sobretudo o discurso universitário e também o discurso do mestre, em nossos dias atuais. Lacan, anos após proferi-los das primeiras vezes, continuou marcando a sua força no modo em que constrói os laços. Entendemos que o sujeito, cuja estrutura atravessa a história da humanidade, ainda continua construindo suas subjetividades em cada momento histórico, cuja peculiaridade de cada contingência faz vigorar alguns de seus modelos discursivos que sempre o acompanharam. Portanto, o esquema parece continuar sobre quatro patas, não somente quanto aos 
lugares que podem ser ocupados em um discurso, mas também pelos quatro discursos, que se ocupam dos laços.

R. Inter. Interdisc. INTERthesis, Florianópolis, v.14, n.2, p.39-56 Mai.-Ago. 2017 


\title{
PARADOXES OF THE CAPITALIST DISCOURSE: A NEW SUBJECT?
}

\begin{abstract}
:
This article proposes, based on Jacques Lacan's theory of discourses, a questioning about the capitalist discourse in the matheme form presented in 1972, by the occasion of Milan's Conference. The capitalist discourse had already been mentioned by the author in another form, especially in the Seminar 17, "The other side of psychoanalysis" (1969/1970), when he pointed it as a variant of the discourse of the master. Herein, Lacan always referred to this discourse by emphasizing the difference between the modern master (capitalist) and the traditional master (lord), albeit both occupying similar positions, that is, revealing the same configuration of relationship in the social bond. In 1972, on the other hand, in the conference above mentioned, Lacan proposed the matheme of the capitalist discourse, yet he pointed out that this form would be condemned to consume itself, and therefore not to sustain its own existence. We then question the possibility of the capitalist discourse existence as an unprecedented expression of the subject's relation which has never occurred in any other historical moment.
\end{abstract}

Keywords: Surplus-Value. Surplus-Jouissance. Capitalist Discourse. Marx. Lacan

\section{PARADOJAS DEL DISCURSO CAPITALISTA: ¿UN NUEVO SUJETO?}

\section{Resumen:}

Este artículo propone, a partir de la teoría de los discursos de Jacques Lacan, un cuestionamiento sobre el discurso capitalista en la forma del matema que fue presentado en 1972, con ocasión de la Conferencia de Milán. El discurso capitalista ya había sido mencionando anteriormente, pero bajo otra forma por Lacan, principalmente en el Seminario 17, "El reverso del psicoanálisis" (1969/1970), cuando lo apuntó como una variante del discurso del maestro. En ese contexto, el autor siempre se refirió a ese discurso resaltando la diferencia entre el maestro moderno (capitalista) y el maestro tradicional (señor), pero ambos ocupando posiciones semejantes, o sea, revelando una misma configuración de relación en el lazo social. Ya en 1972, en la conferencia anteriormente citada, Lacan propuso el matema del discurso capitalista pero resaltó que esa forma estaría condenada a consumirse a ella misma y por tanto a no sustentar su propia existencia. Cuestionamos entonces la posibilidad de la existencia del discurso capitalista como expresión de una forma inédita de relación de sujeto jamás ocurrida en otro momento histórico.

Palabras Clave: Plus Valía. Plus de Gozar. Discurso Capitalista. Marx. Lacan. 


\section{REFERÊNCIAS}

ASKOFARÉ, S. (1991). O sintoma social. In: GOLDENBERG, R. (org.).Goza!: capitalismo, globalização, psicanálise. Salvador: Ágalma, 1997. p. 164-189.

BRAUNSTEIN, N. "O discurso capitalista: quinto discurso? O discurso dos mercados (PST): sexto discurso?". In: A Peste: Revista de Psicanálise, Sociedade e Filosofia, v. 2 , n. 1, jan./jun. 2010, p. 143-165.

CEVASCO, R. El discurso del amo. In: MAZA, C. P. et. al. Los discursos de Lacan: seminario del Colegio de Psicoanálisis de Madrid. Madrid: Colegio de Psicoanálisis de Madrid, 2007.

LACAN, J. (1969-1970). O seminário, livro 17: o avesso da psicanálise. Rio de Janeiro: Jorge Zahar, 1992.

LACAN, J. (1972/1978). Traducción de la Conferencia de Lacan en Milán del 12 de mayo de 1972. Tradução de Olga Mabel Máter. In: ELSIGMA. Disponível em http://www.elsigma.com/historia-viva/traduccion-de-la-conferencia-delacan-en-milandel-12-de-mayo-de-1972/9506 Acesso 2 de julho de 2008.

LACAN, J.. (1974). Televisão. Rio de Janeiro: Jorge Zahar, 1993.

MARX, K. (1890). O capital. Rio de Janeiro: Civilização Brasileira, 2012.

NETTO, J. P; BRAZ, M. (2006). Economia política: uma introdução crítica. São Paulo: Cortez, 2011.

PACHECO FILHO, R. A. O frenesi teórico sobre o sujeito do capitalismo tardio. In: RUDGE, A. e BESSET, V. (orgs). Psicanálise e outros saberes. Cia. De Freud/ FAPERJ, 2012; Rio de Janeiro. p. 183-205.

\section{Artigo:}

Recebido em 01 de Outubro de 2016.

Aceito em 29 de Março de 2017. 